\title{
A Decade of Diabetes Hospitalizations: Meaningful Information for Community-Based Health Services Administrators for Identifying and Assessing Risk
}

\author{
Jewel Shepherd ${ }^{1 *}$, Koren Goodman ${ }^{2}$ and Manasi Sheth-Chandra ${ }^{3}$
}

${ }^{1}$ University of South Dakota, Beacom School of Business, Health Services Administration Program, USA

${ }^{2}$ Department of Surgery, Robert Wood Johnson Barnabas Health, 94 Old Short Hills Road, USA

${ }^{3}$ Old Dominion University, College of Health Sciences, Norfolk, USA

\begin{abstract}
The American Diabetes Association has established that the largest contributor of expenditures related to the cost of care for diabetes is inpatient hospital care. Research has shown that when multiple hospitalizations have been examined, patients diagnosed with diabetes have higher same year readmission rates. Medicare-enrolled patients with coronary artery disease and diabetes who participated in a diabetes management intervention that included self-care behavior instructions and nurse management had fewer emergency room visits and hospitalizations for diabetes related care. In the US, an aging population and expected changes in the ethnic composition prompts an alert to actively address the need for prevention, early detection, reduction of associated complications experienced, and exploration of a cure of the chronic condition of diabetes. This study's purpose was two-fold: to examine the variability in hospitalization rates of diabetes by geographical location and age groups from 2000-2011 to examine any statistically significant relationships. The study further proposes the exploration of low-cost technology mechanisms to reduce diabetes related hospitalizations through the use of mHealth. Practical interventions using mHealth technologies are feasible solutions to addressing virtual prevention efforts and improving the outcomes of care among patients diagnosed with diabetes.
\end{abstract}

Keywords: Diabetes; Hospitalizations; mHealth; Technology-based interventions

\section{Introduction}

Diabetes mellitus is a debilitating, costly chronic condition, with prevalence rates expected to increase through the year 2050 [1]. In the United States (US), an aging population and anticipated changes in the ethnic composition prompts an alert to proactively address preventive measures focused on early detection, lifestyle and behavior modifications, decreasing associated complications experienced, and reducing readmissions using culturally appropriate interventions [2]. Diabetes is a serious public health concern and a societal burden [2]. In 2015, there were approximately 23.1 million diagnosed cases of diabetes among Americans and estimated additional 7.2 million undiagnosed cases [3]. Patients diagnosed with diabetes have health care costs nearly 2.3 times greater compared to individuals without diabetes [4,5]. Direct and indirect expenditures related to the costs of care totaled approximately $\$ 245$ billion in 2012, up from $\$ 98$ billion in 1997 [3-6]. The largest contributor of expenditures related to the cost of care for diabetes is inpatient hospital care [4-7] and hospital readmissions [5].

\section{Diabetes and Hospitalizations in Urban Areas}

With the scientific and clinical developments for prevention, early detection and advanced care, hospital readmission for treatment and therapy is a concern for diabetes care and management costs and quality of life [5]. Shang-Jyh et al. [8] evaluated inappropriate emergency department (ED) use among eight Louisiana hospitals among patients diagnosed with type 2 diabetes. Patients participating in a diabetes management program offering extended office hours, information on how to reduce ED visits for the management of diabetes, and personalized diabetes care management experience a decreased the likelihood of an inappropriate ED visit [8]. Approximately $56 \%$ of visits were identified as less urgent and inappropriately used by patients managing diabetes [8]. Higher utilization rates for less urgent visits were frequent among those patients with four or more co-morbid conditions [8]. The number of multiple hospitalization stays, and ED visits were reduced among Medicare-enrolled patients with coronary artery disease and diabetes who participated in a diabetes management intervention that included self-care behavior instructions and nurse management [9]. Hospital admission rates were slightly higher for participants who did not receive the intervention, suggesting diabetes self-management education and training programs play an integral role in reducing diabetes related complications and inpatient hospital stays.

Jiang et al. [10] examined multiple hospitalizations in five states and found that diabetes patients experienced higher rates of readmissions. More than half of total inpatient hospital stays were diabetes related, and female patients had the highest percent of total stays, accounting for $55 \%$. Additionally, female patients, $18-64$ years, and those 65 years and older experienced higher rates of readmissions. Compared to males, females diagnosed with diabetes have multiple hospitalizations as a result of complications experienced from diabetes [10]. Patients with government sponsored insurance accounted for the highest percent of hospital stays compared to patients with private, other insurance, and those uninsured. Regression analyses revealed that

*Corresponding author: Jewel Shepherd, University of South Dakota, Beacom School of Business, Health Services Administration Program, USA. Tel: +605-658-6548; E-mail: Jewel.Shepherd@usd.edu

Received November 23, 2017; Accepted December 19, 2017; Published December 26, 2017

Citation: Shepherd J, Goodman K, Sheth-Chandra M (2017) A Decade of Diabetes Hospitalizations: Meaningful Information for Community-Based Health Services Administrators for Identifying and Assessing Risk. J Pat Care 3: 135. doi: 10.4172/2573-4598.1000135

Copyright: (c) 2017 Shepherd J, et al. This is an open-access article distributed under the terms of the Creative Commons Attribution License, which permits unrestricted use, distribution, and reproduction in any medium, provided the original author and source are credited. 
government sponsored insured, Hispanics, non-Hispanic Blacks and patients from zip codes identified as low-income areas were significant predictors of multiple hospitalizations [10,11]. Kim et al. [5] observed similar disparity findings in that living in low-income, urban areas, having government sponsored or public insurance, and ethnicity were stronger predictors of unscheduled readmissions. Of the total sample population $(\mathrm{n}=124,967)$, results showed $87 \%$ were unscheduled admits, with $26 \%$ being readmitted within 90 days [10]. These findings support emphasis being placed on increasing efforts to increase quality selfcare management behavior modifications in outpatient settings to decrease readmission rates $[8,11,12]$. While prevention is a preferred method of treatment [13], meaningful compliance, on-going training, education, and support improves quality of life and decreases morbidity and mortality among those diagnosed [14-16]. To reduce the disparity, the impact and the number of uncontrolled and undiagnosed cases of diabetes, access to care remains vital.

\section{Diabetes and Health Care Centers}

There existed a number of proponents who believed the Patient Protection and Affordable Care Act (PPACA) would lessen some of the responsibility of federally qualified health centers in providing lowcost yet high-quality care in underserved areas [17]. In establishing the new roles of Health Care Centers (HCCs) with the passing of the PPACA, HCCS are expected to expand their current service delivery models to take a novel approach at health education and promotion $[17,18]$. HCCs have taken a lead role in the initiation of cost-effective and resource-sharing projects to increase access to care for diabetes management and treatment [19]. HCCs strive to achieve a seamless fluidity of health services delivery that is both accessible and affordable for the surrounding community. In the history of their service role, HCCs serve as community builders and agents for change by partnering with other service organizations to improve care coordination and navigation while lessening the duplication of service bureaucracy [19].

In a study of publicly-funded health centers, data was collected from an urban city specific to diabetes related hospital discharges for the purpose of examining the impact of HCCs in reducing readmissions after hospitalizations [18]. The analysis revealed that patients who participated in usual care at an HCC were less likely to experience a readmission. The provision of care at an HCC for low income and uninsured patients prevented hospital readmissions among this group [18]. HCCs have further developed care models that provide adequate assessments and ultimately corresponding plans to meet the needs of patients and the local community to eliminate the disparities that exist in health care access among the medically underserved by offering a more comprehensive health care delivery model [19]. There still exists a strong need to increase awareness and cultivate healthy environments, prevent premature deaths and avoid disabilities among those populations that experience a disproportionate rate. In reaching out to serve communities, more creative strategic thinking coupled with practical applications alongside accessibility and affordability will be necessary [19].

\section{Diabetes and Self-management with mHealth Technology}

The success of clinic-based care initiatives that incorporate behavioral health education and self-care prompts depends heavily on patient engagement and technology usability [20]. Self-care management will be an ongoing activity for persons diagnosed with diabetes. As such, there is an uncertain future in determining the length of time that these activities will continue. Patient perception, satisfaction, and continuous usage must reside at a high level. These facets can be impacted by clinician support, enhanced capabilities, confidence in self-management abilities, and indefinite use compliance [21]. In a study among participants with uncontrolled diabetes, patients were randomized into one of three intervention groups: the personal digital assistant (PDA), the Chronic Disease Self-Management (CDSM) program, a combination of PDA and CDSM, or the usual care group. The analysis recognized the significant ability of diabetes focused selfmanagement programs utilizing mHealth technologies to delay time to hospitalization [22]. mHealth technology based interventions represent a realistic and convenient method for self-management support systems for diabetes [23]. A randomized control trial demonstrated real-time continuous glucose monitoring (RT-CGM) was a cost-effective measure as a self-management tool to reduce $\mathrm{AlC}$ levels. On-going primary care surveillance, continuity of care, lifestyle modifications, and both pharmaceutical and non-pharmaceutical therapies can delay or reduce costs, complications, hospitalizations and readmissions experienced from diabetes [19].

\section{Purpose of the Study}

This study (1) examined the variability in hospitalization rates of diabetes by geographical location and age from 2000-2011, and (2) explored low-cost technology mechanisms to reduce diabetes related hospitalizations through the use of mHealth. The following research questions were addressed:

- Does a statistically significant relationship exist among hospitalizations of patients diagnosed with diabetes and geographical location?

- Does a statistically significant relationship exist among age categories and hospitalizations of patients diagnosed with diabetes?

- Does a statistically significant relationship exist between age categories and geographical location and hospitalizations among patients with diabetes?

\section{Methodology}

\section{Data source}

The annual number of hospital discharges with the ICD-9-CM code of 250, diabetes and crude hospitalization rates and age specific rates by zip code between 2000-2011 were abstracted from the hospital discharge dataset from the Chicago Department of Public Health. Additionally, the number of residents in each of the zip codes from the city of Chicago stratified by age groups were utilized from the US Census 2000. Veteran hospital discharge data were excluded from the data.

\section{Data analysis}

The first goal was to determine if a statistically significant relationship existed among hospitalizations of patients diagnosed with diabetes and geographical location. The annual number of hospitalizations for the years 2000-2010 were summed and divided by the US Census 2000 Population to obtain location-specific hospitalization rates (per 1000 residents) for each of the zip codes [24]. Ninety-five percent (95\%) confidence intervals for the location-specific hospitalization rates were calculated using binomial to normal approximation under theory of large sample. The second goal was to determine if a relationship existed among age categories and hospitalizations of diabetes patients. The 
Citation: Shepherd J, Goodman K, Sheth-Chandra M (2017) A Decade of Diabetes Hospitalizations: Meaningful Information for Community-Based Health Services Administrators for Identifying and Assessing Risk. J Pat Care 3: 135. doi: 10.4172/2573-4598.1000135

Page 3 of 8

annual number of hospitalizations for the individual years of 2000 2010 was added to obtain the total number of hospitalizations. The total number of hospitalizations was then divided by the number of residents in each zip code to obtain age-group-specific hospitalization rates (per 1000 residents) for each of the age-groups. The hospitalization rates were then averaged for all the zip codes within each of the agegroups. Confidence intervals at $95 \%$ for these hospitalization rates were calculated using binomial to normal approximation under theory of large sample [25]. An overlap between the confidence intervals was considered to be significantly not different from each other. However, if the confidence intervals for any two groups did not overlap, then the groups were considered to be significantly different from each other.

\begin{tabular}{|c|c|c|c|c|}
\hline $\begin{array}{c}\text { ZIP } \\
\text { code(s) }\end{array}$ & $\begin{array}{l}\text { U.S. } 2000 \\
\text { Census } \\
\text { Population }\end{array}$ & $\begin{array}{l}\text { Location-specific } \\
\text { Hospitalization } \\
\text { Rates (per 1000) }\end{array}$ & $\begin{array}{c}\text { Location- } \\
\text { specific Rate } \\
95 \% \text { Lower Cl }\end{array}$ & $\begin{array}{l}\text { Location- } \\
\text { specific Rate } \\
95 \% \text { Upper Cl }\end{array}$ \\
\hline 60621 & 35912 & 73.875 & 71.170 & 76.580 \\
\hline 60636 & 40916 & 65.671 & 63.271 & 68.071 \\
\hline 60624 & 38105 & 63.482 & 61.034 & 65.930 \\
\hline 60628 & 72202 & 63.142 & 61.368 & 64.916 \\
\hline 60644 & 48648 & 62.243 & 60.096 & 64.390 \\
\hline 60649 & 46650 & 60.686 & 58.519 & 62.853 \\
\hline 60653 & 29908 & 59.884 & 57.195 & 62.573 \\
\hline 60620 & 72216 & 57.259 & 55.564 & 58.954 \\
\hline 60619 & 63825 & 56.075 & 54.290 & 57.860 \\
\hline 60651 & 64267 & 52.017 & 50.300 & 53.734 \\
\hline 60617 & 84155 & 45.262 & 43.857 & 46.667 \\
\hline 60612 & 33472 & 44.515 & 42.306 & 46.724 \\
\hline 60643 & 49952 & 44.042 & 42.243 & 45.841 \\
\hline 60637 & 49503 & 41.614 & 39.855 & 43.373 \\
\hline 60609 & 64906 & 34.573 & 33.167 & 35.979 \\
\hline $\begin{array}{c}60827 \text { and } \\
60633\end{array}$ & 40873 & 32.613 & 30.891 & 34.335 \\
\hline $\begin{array}{c}60622 \text { and } \\
60642\end{array}$ & 71028 & 32.424 & 31.121 & 33.727 \\
\hline 60647 & 87291 & 32.397 & 31.222 & 33.572 \\
\hline 60623 & 92108 & 32.006 & 30.869 & 33.143 \\
\hline 60615 & 40603 & 28.298 & 26.685 & 29.911 \\
\hline 60639 & 90407 & 28.018 & 26.942 & 29.094 \\
\hline 60640 & 65790 & 27.466 & 26.217 & 28.715 \\
\hline 60616 & 48433 & 27.275 & 25.824 & 28.726 \\
\hline $\begin{array}{c}60707 \text { and } \\
60635\end{array}$ & 42920 & 27.144 & 25.607 & 28.681 \\
\hline 60652 & 40959 & 25.953 & 24.413 & 27.493 \\
\hline 60608 & 82739 & 24.837 & 23.777 & 25.897 \\
\hline 60626 & 50139 & 24.831 & 23.469 & 26.193 \\
\hline 60629 & 113916 & 24.685 & 23.784 & 25.586 \\
\hline 60660 & 42752 & 24.654 & 23.184 & 26.124 \\
\hline 60638 & 55026 & 21.826 & 20.605 & 23.047 \\
\hline 60645 & 45274 & 18.951 & 17.695 & 20.207 \\
\hline 60632 & 91326 & 18.242 & 17.374 & 19.110 \\
\hline 60641 & 71663 & 17.875 & 16.905 & 18.845 \\
\hline 60625 & 78651 & 17.775 & 16.852 & 18.698 \\
\hline 60646 & 27177 & 17.073 & 15.533 & 18.613 \\
\hline 60618 & 92084 & 16.583 & 15.758 & 17.408 \\
\hline 60656 & 27613 & 16.297 & 14.804 & 17.790 \\
\hline 60630 & 54093 & 16.028 & 14.970 & 17.086 \\
\hline 60634 & 74298 & 15.976 & 15.074 & 16.878 \\
\hline
\end{tabular}

\begin{tabular}{|c|c|c|c|c|}
\hline $\begin{array}{c}60610 \text { and } \\
60654\end{array}$ & 52601 & 15.893 & 14.824 & 16.962 \\
\hline 60659 & 38104 & 15.616 & 14.371 & 16.861 \\
\hline 60655 & 28550 & 15.552 & 14.117 & 16.987 \\
\hline 60631 & 28641 & 15.432 & 14.004 & 16.860 \\
\hline $\begin{array}{c}60601, \\
60602, \\
60603, \\
60604, \\
60605 \text { and } \\
60611\end{array}$ & 44403 & 14.301 & 13.197 & 15.405 \\
\hline 60613 & 48281 & 14.084 & 13.033 & 15.135 \\
\hline 60614 & 66617 & 11.333 & 10.529 & 12.137 \\
\hline $\begin{array}{c}60606, \\
60607 \text { and } \\
60661\end{array}$ & 33997 & 10.530 & 9.445 & 11.615 \\
\hline 60657 & 65996 & 8.516 & 7.815 & 9.217 \\
\hline Total & 2728990 & 31.559 & 31.351 & 31.766 \\
\hline
\end{tabular}

Table 1: Chicago hospitalization location - Specific rates stratified by ZIP code(s).

\begin{tabular}{|c|c|c|c|}
\hline Age Groups & $\begin{array}{c}\text { Mean } \\
\text { Hospitalization } \\
\text { Rate (per 1000) }\end{array}$ & $\begin{array}{c}\text { Mean } \\
\text { Hospitalization } \\
\text { Rate 95\% Lower Cl }\end{array}$ & $\begin{array}{c}\text { Mean } \\
\text { Hospitalization } \\
\text { Rate 95\% Upper Cl }\end{array}$ \\
\hline Under 5 years & 510.80 & 432.773 & 588.832 \\
\hline 5 to 9 years & 591.391 & 508.015 & 674.768 \\
\hline 10 to 14 years & 611.943 & 525.576 & 698.310 \\
\hline 15 to 19 years & 512.848 & 450.014 & 575.681 \\
\hline 20 to 24 years & 459.308 & 374.463 & 544.153 \\
\hline 25 to 29 years & 450.139 & 349.120 & 551.082 \\
\hline 30 to 34 years & 475.856 & 370.100 & 581.612 \\
\hline 35 to 39 years & 502.879 & 401.330 & 604.429 \\
\hline 40 to 44 years & 532.360 & 435.022 & 629.698 \\
\hline 45 to 49 years & 518.893 & 437.232 & 600.713 \\
\hline 50 to 54 years & 526.792 & 448.211 & 605.373 \\
\hline 55 to 59 years & 619.167 & 524.951 & 716.383 \\
\hline 60 to 64 years & 763.023 & 640.608 & 885.439 \\
\hline 65 to 69 years & 1061.353 & 898.447 & 1224.259 \\
\hline 70 to 74 years & 1363.176 & 1167.777 & 1558.575 \\
\hline 75 to 79 years & 1796.102 & 1534.520 & 2057.684 \\
\hline 80 to 84 years & 2420.89 & 2019.645 & 2822.135 \\
\hline 85 years or & 2799.661 & 2224.752 & 3374.570 \\
\hline above & & & \\
\hline
\end{tabular}

Table 2: Mean hospitalization (per 1000) rate stratified by age groups ( $\mathrm{n}=48$ each).

\section{Results}

Table 1 displays the crude rates as well as the 95\% upper and lower confidence intervals for hospitalizations of an urban city in the US stratified by zip code(s). The crude rates for the zip code(s) 60621,60636 and 60651 were significantly different from each other as well as from the other zip code(s). Significant results were not obtained for the zip code(s) when compared with at least one other zip code(s). A possible limitation in utilizing this calculation is that the population may not be representative of the actual population for each of the zip codes over the years 2000-2010 since the number of residents being hospitalized annually may not be unique from year-to-year. The actual number of residents was unavailable for each year; therefore, actual hospitalization rates may be an underestimate compared to those provided in Table 1.

Table 2 shows the hospitalization rate on average for the various age groups. Each age group had hospitalizations rates reported for 48 different zip codes for the city of Chicago. These rates were then 
averaged to obtain a mean hospitalization rate per 1000 residents for each of the zip codes. 95\% confidence intervals are also provided for each of the age groups. Results demonstrated that the mean hospitalization rate per 1000 residents was significantly higher for ages 65 or above as observed in Figure 1. The confidence intervals for these age groups were wider possibly due to the variability of health conditions amongst these "older" age groups.

Figures $2 \mathrm{a}-2 \mathrm{f}$ shows the hospitalization rates on an average for the years 2000 to 2011 stratified by zip codes. Each line represents the crude hospitalizations rates reported for each of the 48 different zip codes for the city of Chicago. There were clusters of zip codes with substantial changes in their crude hospitalization rates over the period of 12 years: $60612,60617,60621,60622 ; 60642,60637,60827$; and 60653, 60633 and 60660. To explain, zip codes cluster 60612, 60617, 60621 and 60622 have a low socioeconomic status with the average household income of those areas as $\$ 29,721$ annually; and for 60653,60633 and 60660 , at $\$ 29,763$ with at least one zip code in each of the clusters populated with more than $98 \%$ non-Hispanic Blacks (Table 3).

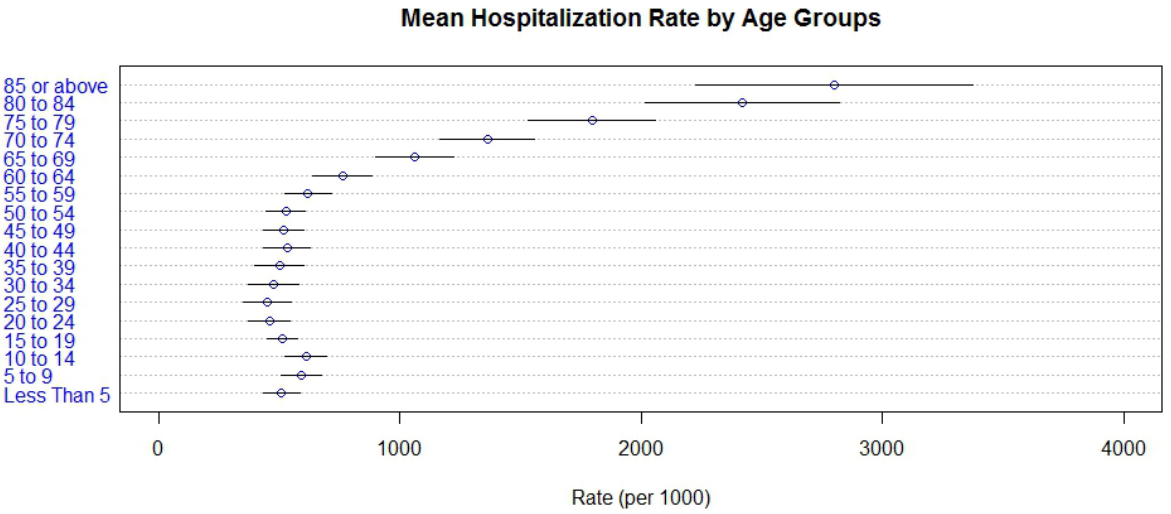

Figure 1: Mean hospitalization rate by age groups.
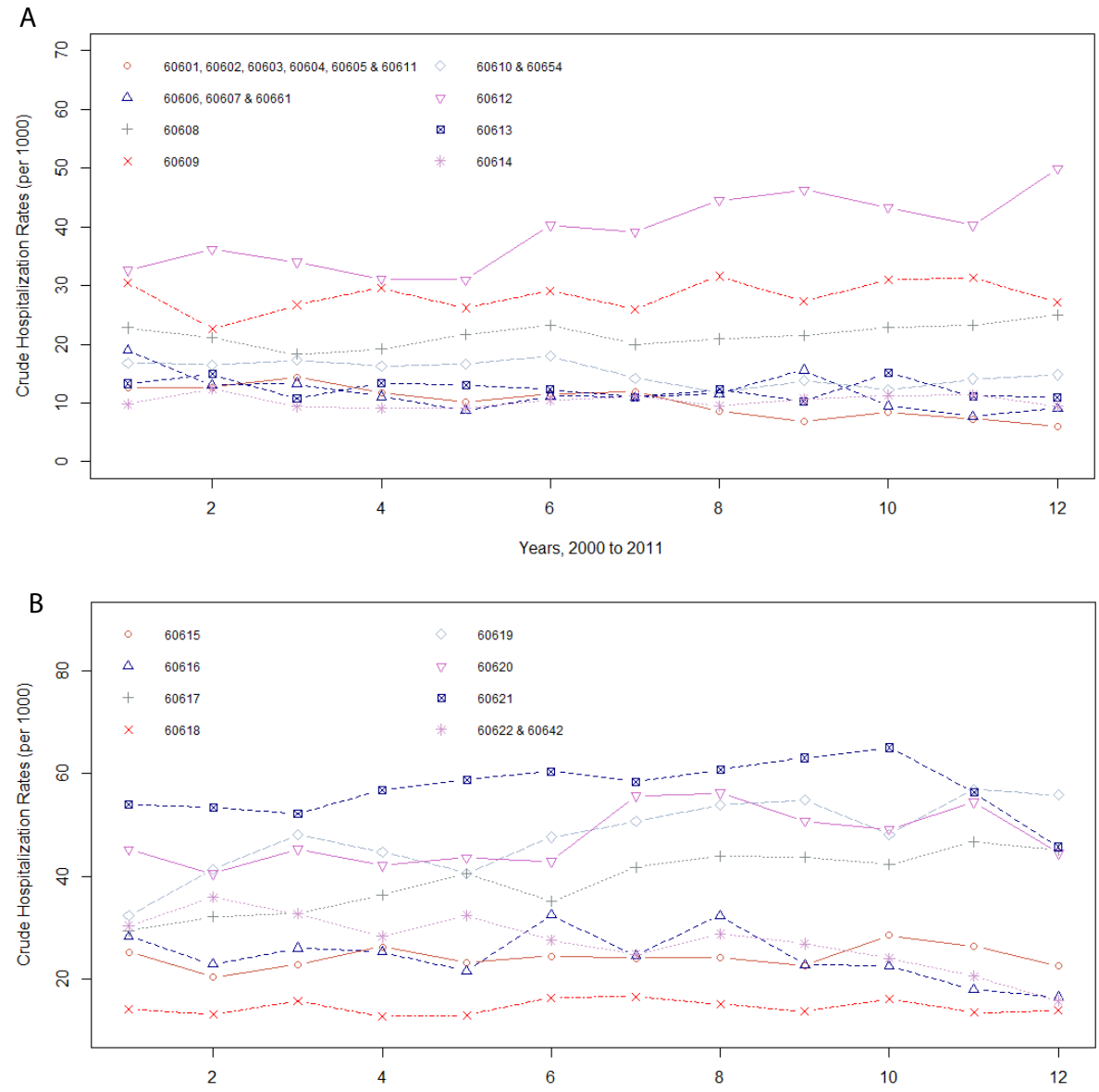


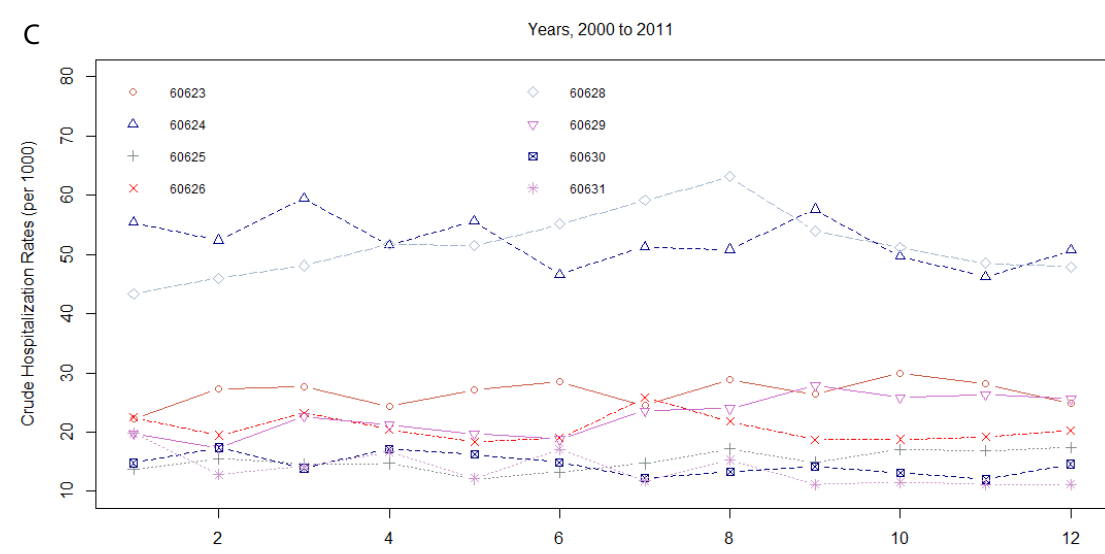

$\mathrm{D}$

Years, 2000 to 2011
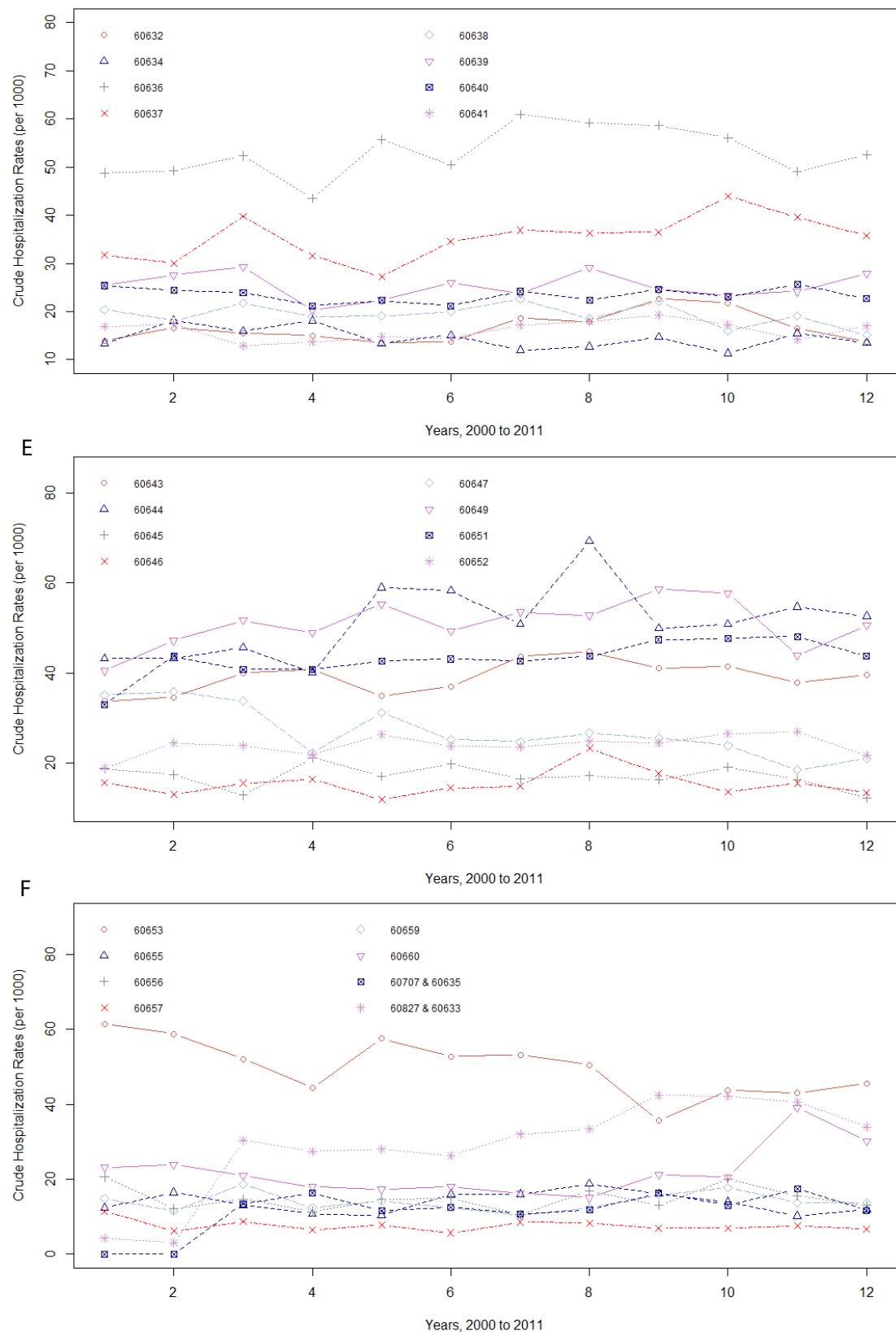

Figure 2: Crude hospitalization rates (per 1000), years 2000 to 2011. 


\begin{tabular}{|c|c|c|c|}
\hline $\begin{array}{c}\text { ZIP } \\
\text { Code } \\
\text { Clusters }\end{array}$ & Population & $\begin{array}{c}\text { Percentage of } \\
\text { Non-Hispanic } \\
\text { Blacks } \\
\text { (\%) }\end{array}$ & $\begin{array}{c}\text { Mean Household } \\
\text { Annual Income } \\
\mathbf{( \$ )}\end{array}$ \\
\hline 60612 & 37,990 & 65.57 & 25,143 \\
60617 & 96,288 & 54.56 & 35,534 \\
60621 & 47,514 & 98.19 & 19,718 \\
60622 & 76,015 & 10.94 & 38,487 \\
\hline 60637 & 57,090 & 82.24 & - \\
60642 & - & - & - \\
60827 & - & - & - \\
\hline 60633 & 13,262 & 18.63 & 40,792 \\
60653 & 34,502 & 97.91 & 14,205 \\
60660 & 47,726 & 17.81 & 34,293 \\
\hline
\end{tabular}

Table 3: ZIP codes cluster by population, percentage of non-Hispanic blacks and mean household income.

\section{Discussion and Conclusion}

Coordinated care processes reduce inappropriate emergency department services utilization in addition to improving clinical processes and outcomes $[8,15]$. This study demonstrated that hospitalizations of patients with diabetes crude rates for the zip code(s) 60621, 60636 and 60651 were significantly different from each other as well as from the other zip code(s). The data shows that the mean hospitalization rate per 1000 residents were significantly higher for ages 65 or above.

\section{Preventable hospitalization rates}

Preventable hospitalization rates by neighborhood poverty decreased from 2008 to 2013 among a studied region in a northeastern state of the US [26]. Bocour [26] evaluated gaps between very high and low poverty neighborhoods by examining trends over a fiveyear period. Information specific to demographic groups identified as having higher rates of preventable hospitalizations is beneficial to geographically identify areas for improvement in access to primary care. Although hospitalization rates decreased during the five-year period, disparities remained among gender, race, socioeconomic status, access and complications due to lack of self-management. Such findings underscore the need to improve adequate access to quality and timely primary care for individuals residing in low-sociodemographic areas and communities [26]. Cost effective diabetes care incorporates measures that are on-going, efficient and safe [7]. Treatment modalities may include those that are offered in the patient's primary medical home, technology based, practical, age specific, and those that are culturally sensitive with targeted audiences [2,7,27-29]. Practical technological interventions using mHealth technologies are feasible solutions to addressing virtual prevention efforts and improving the outcomes of care among patients diagnosed with diabetes.

\section{Technology based interventions, the challenges that yet exist}

There is a growing preference of mobile technology use among patients expected to actively participate in self-managed care. Integrating access to resources seamlessly into patients' daily lives through the use of technology improves engagement in self-care management. With the more than 700 mobile applications geared toward diabetes, an evaluation is warranted to review the usability and clinical achievements of these interventions [30]. Patient-centered medical homes are increasingly offering a myriad of interprofessional approaches to address continuity of care as it relates to the self-care management of chronic diseases such as diabetes. Issues such as connectivity, cost, and the forethoughts of challenges yet to be determined are the concerns that lay ahead.

\section{Collaborative care approach}

Because diabetes is a debilitating disease, providers are instrumental in connecting patients to lifestyle modifications to reduce the associated complications experienced [24,25,31]. Patient centered medical homes are particularly appropriate for patients managing diabetes to receive ongoing surveillance and a team centered approach to support prevention and wellness. The facilitation of integrated care is coordinated through the medical home, as the primary care provider authorizes specialty referrals as required by many health maintenance organization [32-35]. A study evaluating the link between mortality and healthcare utilization effects of an intervention that combined care management and telehealth integrated a content-driven telehealth system with care management [32]. The target population included patients diagnosed with congestive heart failure, chronic obstructive pulmonary disease, and / or diabetes living in the northwest area of the US The "Health Buddy" program participants experienced reductions in risk-adjusted all-cause mortality and in the number of quarterly inpatient admissions. The study concluded that care management combined with content-driven telehealth technology has great potential in improving health outcomes among high-cost Medicare beneficiaries [32].

Absent a model that involves the possible interaction and effects of all of the body's systems, a patient could experience increased risks for further preventable complications of the chronic condition diabetes [32]. Healthcare delivery has been redesigned to acknowledge the need for interdisciplinary approaches to structuring programs that meet the varying needs of patients, particularly those in underserved communities, to lessen the impact of poor care management at the individual and system level. Davis et al. [36] defined inter-professional education as those opportunities for multiple professionals to both learn from and about one another's responsibilities to providing overall quality care. This occasion for sharing in the tasks of problem solving and decision making enhances the goal of increased service for the patient and increased participation and communication among the involved professionals. Diabetes is a model illness for chronic disease management that requires inter-professional collaboration [32].

\section{Identifying and assessing risk for culturally appropriate interventions}

Ethnic minority groups diagnosed with diabetes are disproportionately affected by diabetes and associated complications of this debilitating disease. As such, there is an increasing need to develop interventions focused on prevention and those that address disparities. Additionally, ethnic minorities are often vulnerable and receive inadequate care as a result of factors associated with educational barriers, linguistic differences, religious, health, and illness beliefs often unfamiliar to mainstream society. Patient-centered, culturally competent interventions are required to effectively maximize opportunities to deliver compassionate care, healthcare excellence, quality health services, and cost-effective care. Addressing the patient's behaviors, needs, and beliefs from a culturally competent perspective will yield improved diabetes-related clinical outcomes among ethnic minority populations. In a study examining the risk for developing diabetes, reports showed that interventions comprised of aggregated electronic health records reviewed by a routine centralized reporting of patient-level data was successful in providing a novel approach to identifying at-risk communities and providing targeted, communitybased interventions. Reports focused on such patient level performance measures as hemoglobin AlC (HgbAlc). The authors examined geographic variation in $\mathrm{A} 1 \mathrm{C}$ among participants residing of two urban and one rural county in a Midwestern state of the US [37] 
Citation: Shepherd J, Goodman K, Sheth-Chandra M (2017) A Decade of Diabetes Hospitalizations: Meaningful Information for Community-Based Health Services Administrators for Identifying and Assessing Risk. J Pat Care 3: 135. doi: 10.4172/2573-4598.1000135

Page 7 of 8

Essential to diabetes care are self-care practices, lifestyle modifications, and quality clinical preventive care management $[38,39]$. When compared to standard or even a non-mHealth approach, technology based interventions can impact positively glycemic control among patients with diabetes. mHealth shows potential as a diabetes selfmanagement tool that will aid clinical decision making and improve patient outcomes [40-41]. As such, these technologies are increasingly becoming standard in clinical practice. Of importance is the necessity to utilize free mobile applications requiring minimal cost and having ease of use. Particularly, users normally prefer those free mobile applications that do not require internet connection and consist of all the desired features in a single function. Because the availability and quality of mobile health techniques and usability have been increasing as a result of the high usage of mobile devices in clinical practice, newly appointed health services administrators should be inclined to consider its usefulness in health education, promotion and maintenance regimens offered by clinicians and lay professionals for increasing positive outcomes among patients managing chronic conditions. The data presented here are a useful tool for identifying geographic areas with increased rates of avoidable hospitalizations and readmissions that require increased access to quality primary care and education on better health maintenance with self-management tools.

\section{References}

1. Boyl JP, Thompson TJ, Gregg EW, Barker LE, Williamson DF (2010) Projection of the year 2050 burden of diabetes in the US adult population: Dynamic modeling of incidence, mortality and prediabetes prevalence. Popul Health Metr 8: 29.

2. Caspersen C, Thomas G, Boseman L, Beckles G, Albright A (2012) Aging diabetes and the public health system in the United States. Am J Public Health (N Y) 102: 1482-1497.

3. American Diabetes Association (2017) Statistics about diabetes. Ann Intern Med $167: 493-498$.

4. American Diabetes Association (2013) Economic costs of diabetes in the U.S. in 2012. Diabetes Care 36: 1033-1046.

5. Kim H, Ross J, Melkus G, Zhao Z, Boockvar K (2010) Scheduled and unscheduled hospital readmissions among diabetes patients. Am J Manag Care 16: 760-767.

6. American Diabetes Association (1998) Economic consequences of diabetes mellitus in the U.S. in 1997. Diabetes Care 21: 296-309.

7. Coto J, Yehle K, Foli K (2014) The relationship between uncontrolled glycemia and the cost of hospitalization. Clin Nurse Spec 28: 283-287.

8. Shang-Jyh C, Campbell C, Myers L, Culbertson R, Horswell R (2010) Factors influencing inappropriate use of ED visits among type 2 diabetics in an evidence-based management programme. J Eval Clin Pract 16: 10481054

9. Rosenzweig JL, Taitel MS, Norman GK, Moore TJ, Turenne W, Tang P (2010) Diabetes disease management in Medicare advantage reduces hospitalizations and costs. Am J Manag Care 16: e157-e162.

10. Jiang H, Stryer D, Friedman B, Andrews R (2003) Multiple hospitalizations for patients with diabetes. Diabetes Care 26: 1421-1426

11. Dungan K (2012) The effect of diabetes on hospital readmissions. J Diabetes Sci Technol 6: 1045-1052.

12. Jiang J, Andrews R, Stryer D, Friedman B (2005) Racial/ethnic disparities in potentially preventable readmissions: The case of diabetes. Am J Public Health (N Y) 95: 1561-1567

13. Knowler W, Barrett-Connor E, Fowler S, Hamman R, Lachin J, et al. (2002) Reduction in the incidence of type 2 diabetes with lifestyle intervention or metformin. N Engl J Med 346: 393-403.

14. Centers for Disease Control and Prevention (2013) Diabetes public health resource.

15. Greisinger A, Balkrishnan R, Shenolikar R, Wehmanen O, Muhammad S, et al.
(2004) Diabetes care management participation in a primary care setting and subsequent hospitalization risk. Dis Manag 7: 325-333

16. World Health Organization (2013) Equity, social determinants and public health programmes.

17. (2013) Kaiser Commission on Medicaid and the Uninsured. Community health centers in an era of health reform: An overview and the key challenges to health center growth, executive summary.

18. Robbins JM, Valdmanis VG, Webb DA, (2008) Do public health clinics reduce rehospitalizations? The Urban Diabetes Study. J Health Care Poor Underserved 19: 562-73

19. Shepherd J G, Lemaster M (2014) Community health centers: Addressing overall health and oral health is a perfect match. Dimens Dent Hyg 12: 60-64.

20. Goodman K (2014) Utilizing the technology acceptance model to predict system use of an interactive behavior change technology to deliver virtua diabetes health education (Doctoral Dissertation). Retrieved from ProQuest. (UMI Number 3581592).

21. Chang CP (2017) Experience of home telehealth technology in older patients with diabetes. Computers, Informatics, Nursing: CIN, Computers, Informatics, Nursing: CIN, Comput Inform 35: 530-537.

22. Bolin A, Zhao P, Phillips CD, Zhao H, Ohsfeldt RL, et al. (2014) Effects of diabetes self-management programs on time-to-hospitalization among patients with type 2 diabetes: A survival analysis model. Patient Educ Couns 95: 111-117.

23. Korey C (2015) Going mobile with diabetes support: A randomized study of a text message-based personalized behavioral intervention for type 2 diabetes self-care. Diabetes Spectr 28: 83-92.

24. Gustafson D, Robinson T, Ansley D, Adler L, Brennan P (1999) Consumers and the evaluation of interactive health communication applications. Am J Prev Med 16: 23-29.

25. Kovner AR, Knickman JR, Jonas S (2009) Jonas and Kovner's health care delivery in the United States $\left(9^{\text {th }}\right.$ ed). New York, NY: Springer Publishing Company, LLC 301: 442

26. Bocour A (2016) Preventable hospitalization rates and neighborhood poverty among New York City Residents, 2008-2013. J Urban Health 93: 974-984.

27. Cha E, Kim K, Umpierrez G, Dawkins C, Bello M, et al. (2014) A feasibility study to develop a diabetes prevention program for young adults with prediabetes by using digital platforms and a handheld device. Diabetes Educ 40: 626-637.

28. Catalani C, Philbrick W, Fraser H, Mechael P, Israelski DM (2013) mHealth for HIV treatment and prevention: A systematic review of the literature. Open AIDS J 13: 17-41.

29. mHealth Alliance (2014) What is mHealth?

30. Yu C H, Parsons J A, Mamdani M, Lebovic G, Hall S, et al. (2014) A webbased intervention to support self-management of patients with type 2 diabetes mellitus: effect on self-efficacy, self-care and diabetes distress. J Biomed Inform 14: 1-26.

31. Sanchez I (2011) Implementation of a diabetes self-management education program in primary care for adults using shared medical appointments. Diabetes Educ 37: 381-391.

32. Baker LC (2013) Effects of care management and telehealth: A longitudinal analysis using Medicare data. J Interprof Care 61: 1560-1568.

33. Pati S, Shea S, Rabinowitz D, Carrasquillo O (2005) Health expenditures for privately insured adults enrolled in managed care gatekeeping vs indemnity plans. Am J Public Health (N Y) 95: 286-291.

34. Continelli T, McGinnis S, Holmes T (2010) The effect of local primary care physician supply on the utilization of preventive health services in the United States. Health Place 16: 942-951.

35. Bojadzievski T, Gabbay RA (2011) Patient-centered medical home and diabetes. Diabetes Care 34: 1047-1053.

36. Davis P, Clackson J, Henry C, Bobyn J, Suveges L (2008) Interprofessional continuing health education for diabetic patients in an urban underserved community. J Interprof Care 22: 51-60.

37. Gabert R, Thomson B, Gakidou E, Roth G, Gorlova O. (2016) Identifying high-risk neighborhoods using electronic medical records: A population-based approach for targeting diabetes prevention and treatment interventions. PLoS One 11. 
Citation: Shepherd J, Goodman K, Sheth-Chandra M (2017) A Decade of Diabetes Hospitalizations: Meaningful Information for Community-Based Health Services Administrators for Identifying and Assessing Risk. J Pat Care 3: 135. doi: 10.4172/2573-4598.1000135

Page 8 of 8

38. Duncan I, Ahmed T, Li Q, Stetson B, Ruggiero L, et al. (2011) Assessing the value of the diabetes educator. Diabetes Educ 37: 638-657.

39. Norris S, Lau J, Smith S, Schmid C, Engelgau M (2002) Self-management education for adults with type 2 diabetes: A meta-analysis of the effect on glycemic control. Diabetes Care 25: 1159-1171.
40. Iyengar $V(2016)$ Challenges in diabetes care: Can digital health help address them? Clin Diabetes 34: 133-142.

41. Kitsiou S (2017) Effectiveness of mHealth interventions for patients with diabetes: An overview of systematic reviews. PLoS One 12: 1-17. 